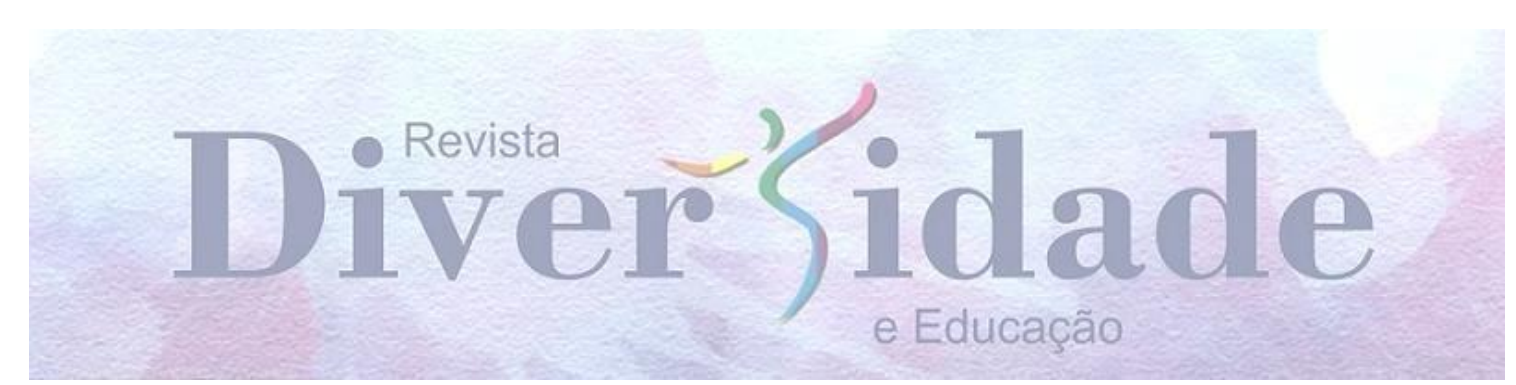

\title{
EDUCAÇÃO SEXUAL NA EDUCAÇत̃O INCLUSIVA: ATITUDES DE PROFESSORES DIANTE DE SITUAÇÕES PROJETIVAS ENVOLVENDO COMPORTAMENTOS SEXUAIS DE ALUNOS ${ }^{1}$
}

\author{
EDUCACIÓN SEXUAL EN LA EDUCACIÓN INCLUSIVA: ACTITUDES \\ DEL MAESTROS EM SITUACIONES QUE INCLUYEN EL \\ COMPORTAMIENTOS SEXUALES DE LOS ESTUDIANTES
}

\section{SEXUAL EDUCATION IN INCLUSIVE EDUCATION: TEACHER'ATTITUDES TOWARDS PROJECTIVE SITUATIONS INVOLVING SEXUAL BEHAVIORS OF STUDENTS}

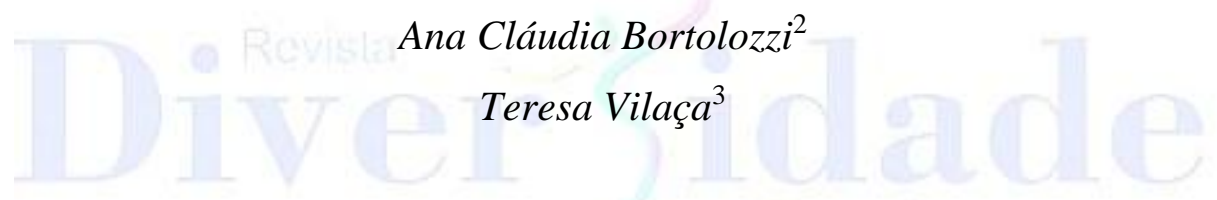

\section{RESUMO}

A Educação Sexual é uma dificuldade para muitos professores nas escolas inclusivas. Este estudo investigou as possíveis atitudes de 55 professores portugueses diante de seis situações projetivas envolvendo o público alvo da educação especial, apresentadas em um questionário, envolvendo diferentes comportamentos sexuais de alunos: autoerotismo (deficiência intelectual- DI), toques indevidos (cego/deficiência visualDV), beijo/namoro (surdez- S), abuso sexual (deficiência física- DF), pergunta sobre sexo na aula (deficiência múltipla- DM) e exibicionismo (autismo-TEA). Diante das situações, as atitudes mais frequentes relatadas pelos professores foram: o "diálogo acolhedor" (TEA e DM), "pedir ajuda" (DF e TEA) e "corrigir comportamentos" (DI e DV); eles não se omitem diante dos comportamentos, mas não refletem porque eles ocorreram, nem como poderiam preveni-los. Conclui-se que, apesar de uma postura favorável à Educação Sexual na escola, é importante investir na formação continuada e as situações projetivas foram procedimentos úteis no levantamento dessa necessidade.

PALAVRAS-CHAVE: Educação Sexual. Educação Especial. Professores. Formação.

${ }^{1}$ Parte Integrante das atividades realizadas em Pós-Doutorado no exterior (Processo Fapesp n.2016/14382-0).

${ }^{2}$ Livre-docente. Universidade Estadual Paulista “Júlio de Mesquita Filho"- UNESP, Bauru, São Paulo,

Brasil.

${ }^{3}$ Doutorado. Universidade do Minho - Uminho, Braga, Minho, Portugal. 


\section{RESUMEN}

La Educación Sexual es una dificultad para muchos maestros en escuelas inclusivas. Este estudio investigó las posibles actitudes de 55 maestros portugueses hacia seis situaciones proyectivas com el público de el educación especial, presentado en un cuestionario, que involucra diferentes comportamientos sexuales de los estudiantes: autoerotismo (discapacidad intelectual - ID), contacto inapropiado (discapacidad visualDV), besos (sordera- S), abuso sexual (discapacidad física- DF), pregunta sobre sexo (discapacidad múltiple- DM) y exhibicionismo (autismo-ASD). En vista de las situaciones, las actitudes más frecuentes informadas fueron: "diálogo" (TEA y DM), "pedir ayuda" (DF y TEA) y "corregir comportamientos" (DI y DV); no se descuidan frente a los eventos, pero no reflexionan sobre por qué los ocurrieron, ni cómo podrían prevenirlos. Se concluye que, a pesar de una postura favorable a la Educación Sexual en la escuela, es importante invertir en educación continua y las situaciones proyectivas fueron procedimientos útiles para elevar esta necesidad.

PALABRAS-CLAVE: Educación Sexual. Educación Especial. Maestros. Formación.

\section{ABSTRACT}

Sexual Education is a difficulty for many teachers in inclusive schools. This study investigated the possible attitudes of 55 portuguese teachers using six projective situations with audience of special education, presented in a questionnaire involving different sexual behaviors of students: autoeroticism (intellectual disability- ID), improper touch (visual impairent- VI), kissing (deafness-D), sexual abuse (physical disability-PD), question about sex (multiple disability - MD) and exhibitionism (autism - ASD). In view of the situations, the most frequent attitudes reported were "welcoming dialogue" (ASD and MD), "asking for help" (PD and ASD) and "correcting behaviors" (ID and VI); they do not neglect themselves in the face of behaviors, but no refletc on why they occurred, nor how they could prevent them. It is concluded that, despite a favorable posture do Sexual Education at school, it is important to invest in teacher's training and the projective situations were useful procedures in raising this need.

KEYWORDS: Sexual Education; Special Education; Teachers; Formation.

$$
* * *
$$

Ensinar não é transferir conhecimento, mas criar as possibilidades para a sua própria produção ou a sua construção.

Paulo Freire

\section{Introdução}

A Educação Sexual na escola é uma questão complexa para muitos professores. Por diferentes razões, tais como morais, religiosas, subjetivas, formativas e estruturais, assumir a Educação Sexual ainda é um desafio, mesmo que o conteúdo de sexualidade seja previsto nos currículos escolares ou que haja a evidência da sua necessidade: o 
aumento dos índices de violência de gênero, de Infecções Sexualmente Transmissíveis (IST) e de gravidezes não planejadas entre alunos (as) cada vez mais jovens.

A Educação Sexual é um processo constante que acontece de modo informal na socialização em diferentes contextos, como a família, os meios de comunicação, a igreja e a escola, e nele envolvem as regras e as normas culturais que mudam ao longo do tempo e da história. Assim, o comportamento sexual humano expressa um processo de aprendizagem sobre os padrões socialmente desejáveis e considerados "normais" em várias expressões da sexualidade: gênero, corpo, estética, conjugalidade etc., em diferentes instâncias sociais (NODIN, 2002; UNESCO, 2014).

Parte desse processo educativo sobre a sexualidade, ocorre de modo formal e organizado, com objetivos pontuais, metas planejadas e diversas ações pedagógicas, chamadas por Nodin (2002) e Maia e Ribeiro (2011) de "propostas intencionais de educação sexual" e, ao longo dos tempos, foram iniciativas que ocorreram nas escolas e, como aponta César (2009), com várias finalidades, em geral, de cunho higienista e profilático.

Maia e Ribeiro (2011) defendem que embora a educação sexual tenha sido pensada na escola pelo viés da prevenção em saúde, ela não deve se limitar a isso, pois a sexualidade deve ser discutida em seus múltiplos aspectos e um processo educativo não pode ser uma mera informação, um mero reproduzir acriticamente de valores sociais hegemônicos, sem oferecer oportunidades de conhecimentos contextualizados que possam ser refletidos, no sentido de formação de atitudes. Assim, uma educação sexual

deveria fornecer informações e organizar um espaço onde se realizariam reflexões e questionamentos sobre a sexualidade. Deveria esclarecer sobre os mecanismos sutis de repressão sexual a que estamos submetidos e sobre a condição histórico-social em que a sexualidade se desenvolve. Deveria também ajudar as pessoas a ter uma visão positiva da sexualidade, a desenvolver uma comunicação mais clara nas relações interpessoais, a elaborar seus próprios valores a partir de um pensamento crítico, a compreender melhor seus comportamentos e o dos outros e a tomar decisões responsáveis a respeito de sua vida sexual. Acreditamos que essa postura crítica é fundamental para a formação de atitudes preventivas e saudáveis sobre a sexualidade (MAIA; RIBEIRO, 2011, p. 79).

Na mesma direção, Matos, Reis, Ramiro, Ribeiro e Leal (2014), Nodin (2002), Vilaça, (2017) e a Unesco (2014) defendem a importância da Educação Sexual nas escolas, sendo essa uma prerrogativa legal em vários países, como Portugal, visando a 
promoção de saúde sexual, mas também de formação de atitudes para a prevenção contra violência de gênero ou sexual e a diminuição de vulnerabilidades sociais.

Com o advento do paradigma inclusivo, as escolas têm recebido e atendido a todos os alunos sem distinção, incluindo aí o Público Alvo da Educação Especial (PAEE), ou seja, pessoas com deficiências (intelectual, física, com surdez, com cegueira, com síndromes e com deficiência múltiplas), pessoas com Transtorno do Espectro Autista (TEA) e pessoas com altas habilidades/superdotação (BRASIL, 2008).

Segundo Bortolozzi e Vilaça (2020), a Educação Sexual em uma educação inclusiva exige de professores uma disposição para compreender a sexualidade no desenvolvimento humano, a ocorrência dos comportamentos sexuais em todos os seus alunos, uma formação sobre as especificidades das deficiências ou outras condições envolvidas e um preparo formal, junto com os dirigentes da escola, para assumirem a Educação Sexual em todos os níveis.

A literatura consultada reforça a ideia de que todas as pessoas são sexuadas, na medida em que o erotismo faz parte de todo o ser humano, independentemente de haver uma deficiência ou não ou quaisquer diversidades (COUWENHOVEN, 2007; KAUFMAN; SILVERBERG; ODETTE, 2003; MAIA; RIBEIRO, 2010; VILELA, 2016). Entretanto, ainda vigoram crenças errôneas, chamadas de "mitos" sobre a manifestação dessa sexualidade, quando há uma deficiência. Esses mitos referem-se as ideias sobre uma suposta sexualidade "diferente", quando há uma deficiência e isso ocorre porque é comum atribuir uma sexualidade atípica generalizando uma limitação relacionada à deficiência ao campo da sexualidade.

As pessoas com deficiências são consideradas possuidoras de uma sexualidade exagerada e descontrolável ("hipersexualidade") ou de uma sexualidade ausente, angelical e infantil ("assexualidade"), além de outros mitos, tais como: a incapacidade de estabelecer vínculos amorosos e/ou sexuais ou de ter filhos saudáveis (ANDERSON, 2000; EAST; ORCHARD, 2013; GIAMI, 2004; KAUFMAN et al., 2003; MAIA; RIBEIRO, 2010; VILELA, 2016).

Maia e Vilaça (2019, p.160-161), esclarecem que

Por um lado, entender a sexualidade como algo "infantil" é um modo de diminuir o potencial erótico dessas pessoas e não colaborar para o desenvolvimento emocional e social que lhes deem autonomia que se espera na vida adulta. Ainda que alguns comportamentos sexuais das pessoas com deficiência possam ser considerados inadequados, exibicionistas, desregrados e que não correspondem às regras sociais, isso não faz essas 
pessoas serem desprovidas de sexualidade e/ou terem um corpo ausente de desejos eróticos (...). Por outro lado, entender que a sexualidade das pessoas com deficiência é exagerada e aberrante é uma concepção decorrente da observação de comportamentos grotescos, geralmente ocorridos publicamente e essa visibilidade reforça uma crença de que o desejo sexual é "exagerado" por ser relacionado à deficiência. Mas sabemos que, expostas aos meios educativos sobre a aprendizagem das regras sociais e ao desenvolvimento das habilidades sociais necessárias no convívio, as pessoas com deficiência podem aprender a expressar seus sentimentos e desejos sexuais - iguais aos de todos (as) - de um modo socialmente saudável e gratificante.

Essas crenças existem a partir de julgamentos sociais diante das expressões sexuais consideradas inadequadas que são generalizadas a todas as pessoas com deficiências e estudos mostram que isso ocorre menos pela deficiência em si e mais pela falta de oportunidades educativas e, também, pelo precário desenvolvimento de habilidades sociais e de limitados suportes sociais dessa população (PÉREZ, 2014; VIEIRA; COELHO, 2014; WILD; KELLY; BLACKBURN; RYAN, 2014).

Para França-Ribeiro (2004) a desconstrução dessas ideias errôneas pode colaborar para a diminuição do preconceito social, incentivar políticas públicas sobre saúde sexual e reprodutiva para o público alvo da educação especial, aumentar o acesso às informações e aos serviços de atendimento e a garantia de seus direitos.

Chirawu, Hanass-Hancock, Aderemi, Reus e Henken (2014) acreditam que as atitudes e concepções dos próprios professores diante da expressão sexual de seus alunos direcionam, em grande medida, a relação que será estabelecida na ES proporcionada por eles. Além disso, estudos mostram (ADEREMI, 2014; REUS, HANASS-HANCOCK, HENKEN; BRAKEL, 2015) que os professores têm dificuldades para lidarem com a sexualidade de seus alunos com deficiência no contexto escolar, pois se encontram diante de um duplo tabu social e de suas próprias fragilidades, ambiguidades de sentimentos e valores, além da precária formação na área. Como reagiriam diante de comportamentos complexos que exigem do professor ações em uma Educação Sexual que não tenham sido planejadas? Quais seriam as atitudes de professores que trabalham em escolas em que a Educação Sexual está prevista na legislação?

Para elucidar esses questionamentos, propomos esta pesquisa que teve por objetivo investigar as atitudes de professores diante de situações projetivas envolvendo manifestações da sexualidade de alunos com deficiências intelectual, física e sensoriais e com TEA na escola inclusiva. 


\section{Método}

Esta pesquisa é caracterizada como um estudo qualitativo-descritivo que visa o conhecimento de modo empírico sobre o fenômeno para posterior descrição e análise, sem a intenção de interferir na realidade e, como afirmam Sampieri, Collado e Lucio (2006), é um bom meio de compreender como as pessoas dizem que se comportam e o que pensam sobre determinado assunto.

\section{Participantes}

A amostra foi composta por 55 professores que trabalhavam no norte de Portugal (Minho), sendo 47 mulheres e oito homens; cinco tinham menos de 40 anos, 26 entre 41 e 50 anos; 22 entre 51 e 60 anos e dois mais de 61 anos. Após o levantamento das escolas da cidade de Braga, com seus respectivos dirigentes e contatos, a pesquisadora enviou um e-mail, detalhando os objetivos da pesquisa e solicitando que tal dirigente encaminhasse o mesmo aos seus (suas) professores (as). Após uma semana, além do e-mail, a pesquisadora fez contato telefônico lembrando e reiterando a solicitação. Aguardamos por um período de dois meses o recebimento de modo anônimo dos respondentes que configuraram nossa amostra.

Trinta e cinco professores tinham a Licenciatura como grau mais elevado de formação e 20 uma pós-graduação (Mestrado ou Especialização). A área da formação desses professores eram: Línguas $(n=13)$; Ciências Biológicas e Geologia $(n=11)$; Ciências Exatas (n=9), Magistério e/ou Pedagogia (n=9), Educação Artística, Musical e Esportes $(n=7)$, Ciências Sociais $(n=5)$ e um em Psicologia. Todos os professores estavam a lecionar há mais de seis anos. Muitos atuavam em mais de um nível de escolaridade, de modo que ministravam aulas para alunos de vários ciclos escolares ao mesmo tempo. A maioria dos professores $(n=43)$ concentrava suas disciplinas no $2^{\circ}$ e $3^{\circ}$ ciclos escolares.

\section{Materiais}

Para a coleta de dados utilizamos um questionário elaborado no software SurveyMonkey, que foi testado antes da versão final em situação piloto. Elaboramos, a partir da literatura e da experiência profissional, seis situações relacionadas com a sexualidade, que podem acontecer nas escolas inclusivas, envolvendo pessoas com diferentes condições: deficiência intelectual, deficiência auditiva/surdez, deficiência 
visual/cegueira, deficiência física, deficiência múltipla e o Transtorno do Espectro Autista (TEA). É importante ressaltar que optamos por elaborar situações complexas que retratassem cenas consideradas problemáticas em decorrência de comportamentos inadequados desses alunos, não porque essa seja uma regra dos alunos no ambiente inclusivo, mas para que eventuais comportamentos considerados inadequados pudessem estimular o relato sobre as possíveis ações de professores. Para cada uma das situações, iniciava-se da mesma forma: "Professor (a), o que você faria se". As situações elaboradas são descritas no Quadro 1.

QUADRO 1. Descrição da elaboração das situações projetivas.

\begin{tabular}{|c|c|c|}
\hline $\begin{array}{l}\text { Tema central de } \\
\text { cada Situação }\end{array}$ & $\begin{array}{l}\text { Com quem ocorre o } \\
\text { comportamento e onde }\end{array}$ & $\begin{array}{l}\text { O que era lido aos participantes: } \\
\text { "Professor (a), o que você faria se.... }\end{array}$ \\
\hline $\begin{array}{l}\text { Situação 1- } \\
\text { Autoerotismo } \\
\text { público } \\
\text { (masturbação) }\end{array}$ & $\begin{array}{l}\text { Aluno com deficiência } \\
\text { intelectual e o } \\
\text { comportamento é } \\
\text { presenciado pelos demais } \\
\text { colegas na sala de aula }\end{array}$ & $\begin{array}{c}\text { Entrasse na sala de aula e visse o João, um } \\
\text { garoto com síndrome de Down, com as calças } \\
\text { abaixadas mexendo no seu pênis, na frente dos } \\
\text { demais colegas"? }\end{array}$ \\
\hline $\begin{array}{c}\text { Situação 2- } \\
\text { Toques } \\
\text { Indevidos no outro }\end{array}$ & $\begin{array}{c}\text { Aluno cego e o } \\
\text { comportamento é } \\
\text { presenciado por um } \\
\text { professor na escola. }\end{array}$ & $\begin{array}{l}\text { Estivesse conversando com Mário, seu aluno } \\
\text { cego, e ele passasse a mão no seu corpo dizendo } \\
\text { que queria saber como você era fisicamente"? }\end{array}$ \\
\hline $\begin{array}{c}\text { Situação 3- } \\
\text { Beijo/Namoro }\end{array}$ & $\begin{array}{l}\text { Um aluno e uma aluna com } \\
\text { surdez e o comportamento é } \\
\text { presenciado por uma } \\
\text { funcionária da limpeza na } \\
\text { escola. }\end{array}$ & $\begin{array}{l}\text { Estivesse conversando com Mário, seu aluno } \\
\text { cego, e ele passasse a mão no seu corpo dizendo } \\
\text { que queria saber como você era fisicamente"? }\end{array}$ \\
\hline $\begin{array}{l}\text { Situação 4- } \\
\text { Relato sobre } \\
\text { Abuso/violência } \\
\text { sexual }\end{array}$ & $\begin{array}{l}\text { Uma aluna com deficiência } \\
\text { física e o comportamento é } \\
\text { relatado a um professor na } \\
\text { escola. }\end{array}$ & $\begin{array}{l}\text { Uma aula sobre o corpo humano a aluna } \\
\text { Raquel, que tem distrofia muscular avançada } \\
\text { com grande comprometimento motor, te } \\
\text { contasse em segredo que o seu avô tinha o } \\
\text { costume de mexer no seu corpo quando a } \\
\text { ajudava a tomar banho e a beijava de noite } \\
\text { quando ela estava sozinha deitada na cama”? }\end{array}$ \\
\hline $\begin{array}{c}\text { Situação 5- } \\
\text { Dúvidas sobre sexo }\end{array}$ & $\begin{array}{l}\text { Uma aluna com deficiência } \\
\text { múltipla, e o comportamento } \\
\text { é direcionado a um professor } \\
\text { na sala de aula. }\end{array}$ & $\begin{array}{l}\text { Em uma atividade escolar um aluno falasse } \\
\text { entre os colegas a palavra "sexo", e a Cristina, } \\
\text { uma menina com limitações motoras, espasmos } \\
\text { frequentes, baixa visão e algum } \\
\text { comprometimento intelectual, te perguntasse: } \\
\text { "O que é sexo"? }\end{array}$ \\
\hline $\begin{array}{c}\text { Situação 6- } \\
\text { Exibicionismo }\end{array}$ & $\begin{array}{l}\text { Um aluno com autismo e o } \\
\text { comportamento é } \\
\text { presenciado pelos demais } \\
\text { colegas da sala de aula. }\end{array}$ & $\begin{array}{c}\text { Marcos, um aluno seu com autismo, ficasse } \\
\text { nervoso numa situação de teste escrito (prova), } \\
\text { e começasse a gritar e a tirar a roupa na sala de } \\
\text { aula”? }\end{array}$ \\
\hline
\end{tabular}

Fonte: Bortolozzi e Vilaça (2020). 


\section{Procedimentos}

Os procedimentos éticos em pesquisas foram respeitados. A pesquisa obteve aprovação por um Comitê de ética de uma universidade pública brasileira (Processo n. 1.845.881) e também autorização pelo sistema de Monitorização de Inquéritos no Meio Escolar, no Ministério de Educação de Portugal (inquérito n. ${ }^{\circ} 0604200001$ ).

Os questionários foram enviados por meio de um link por e-mail. Na primeira folha do questionário havia a declaração de Termo de consentimento livre e esclarecido (TCLE) com informações gerais sobre o estudo e, em caso de concordância, o professor dava seguimento no responder. Nas fases seguintes, propunha-se aos professores que se imaginassem diante das situações apresentadas uma a uma e descrevessem o que fariam diante delas. Todas as respostas eram registradas no software e ao final enviadas às pesquisadoras.

A análise dos dados foi realizada, primeiramente, de modo geral e quantitativo, a partir da organização de "classes de respostas", não mutuamente exclusivas e nomeadas pela atribuição de sentidos. As atitudes convergentes foram organizadas em agrupamentos à posteriori, para facilitar a visibilidade quantitativa de como os professores verbalizaram o que supostamente fariam em cada situação. Ressaltamos que as classes de respostas são diferentes da análise de conteúdo temático, sobretudo, por não serem respostas mutuamente exclusivas, o que quer dizer que no relato do professor poderia haver mais de uma resposta categorizada.

A segunda forma de análise foi a análise qualitativa, pautada em cada situação, organizando categorias temáticas emergentes, aqui sim, mutuamente exclusivas, tal como propõe L. Bardin (2011). Todas as respostas foram lidas e agrupadas a partir de temas convergentes, tornaram-se categorias temáticas que representavam "respostas" comuns do grupo em relação à situação proposta. Neste caso, o número de respostas de cada categoria não é representativo, mas sim a existência da categoria e, portanto, para apresentá-las, iremos mostrar apenas um exemplo de relato em cada uma delas, já que temos muitos relatos e seria demasiado fazê-lo neste texto.

\section{Resultados}

Apresentamos os resultados em dois conjuntos: em um primeiro momento geral e quantitativo, a partir da organização quantitativa dos dados de todo o grupo de 
professores nas classes de respostas, para um posterior momento com as categorias temáticas emergentes, de análise de conteúdo, em cada uma das situações.

\section{Análise quantitativa geral diante das situações projetivas}

De modo geral, os (as) professores (as) não se omitem diante das ocorrências e procuram agir com as melhores intenções em relação aos comportamentos os (as) alunos (as) com deficiência e os (as) demais e suas atitudes foram distribuídas nas classes de respostas emergentes sobre as possíveis atitudes relatadas pelos (as) professores (as) nas diferentes situações e nomeadas pelas pesquisadoras foram as seguintes:

(A) Diálogo e acolhimento: tomar uma atitude, conversando com o aluno, tentando acalmá-lo ou explicando que o comportamento não é adequado. Proporcionar algum modo para atender as suas necessidades;

(B) Correção do comportamento: tomar uma atitude, sinalizando e corrigindo o comportamento inadequado, tentando "controlar" e/ou resolver a situação;

(C) Diálogo e Esclarecimento Coletivo: conversar com o aluno e com os demais da sala tentando esclarecer o ocorrido ou pedir a compreensão e a colaboração,

(D) Tolerância: permitir, relativamente, os comportamentos considerando serem pessoas com deficiência; ignorar a situação, "não fazer nada";

(E) Ajuda: pedir ajuda de outras pessoas: psicólogos (as), funcionários (as), diretores (as), outros (as) professores (as) e/ou especialistas em educação especial; encaminhar ou contar o fato para outras pessoas: pais e mães, promotores, etc.

Os resultados dos relatos nessas classes estão na Tabela 1.

TABELA 1 - Classes de respostas e o número de relatos dos (as) professores (as) diante das situações projetivas.

\begin{tabular}{|c|c|c|c|c|c|c|c|}
\hline \multirow[b]{2}{*}{$\begin{array}{l}\text { Situa- } \\
\text { ções }\end{array}$} & \multirow{2}{*}{$\begin{array}{c}\text { Ocorrências } \\
\text { avaliadas } \\
\text { envolvendo o(a) } \\
\text { aluno(a) com } \\
\text { deficiência na escola } \\
(*)\end{array}$} & \multicolumn{6}{|c|}{ Classes de Respostas } \\
\hline & & $\begin{array}{c}\text { Não } \\
\text { sei// } \\
\text { em } \\
\text { branco }\end{array}$ & $\begin{array}{c}\text { Diálogo } \\
\text { Acolhedor } \\
\text { A }\end{array}$ & $\begin{array}{c}\text { Correção } \\
\text { Comporta- } \\
\text { mento } \\
\text { B }\end{array}$ & $\begin{array}{c}\text { Esclarecer } \\
\text { Coletivo } \\
\text { C }\end{array}$ & $\begin{array}{c}\text { Tolerância } \\
\text { D }\end{array}$ & $\begin{array}{l}\text { Pedir } \\
\text { Ajuda } \\
\mathbf{E}\end{array}$ \\
\hline 1 & $\begin{array}{l}\text { Comportamento } \\
\text { inadequado: de } \\
\text { autoerotismo na sala } \\
\text { de aula (DI) }\end{array}$ & 2 & 29 & 30 & 17 & 0 & 6 \\
\hline 2 & $\begin{array}{l}\text { Comportamento } \\
\text { inadequado: toques } \\
\text { corporais indevidos } \\
\text { no(a) professor(a) }\end{array}$ & 6 & 33 & 17 & 0 & 13 & 3 \\
\hline
\end{tabular}




\begin{tabular}{|c|c|c|c|c|c|c|c|}
\hline & (DV) & & & & & & \\
\hline 3 & $\begin{array}{l}\text { Namoro com beijos } \\
\text { no banheiro (DA/S) }\end{array}$ & 7 & 25 & 9 & 0 & 1 & 16 \\
\hline 4 & $\begin{array}{l}\text { Abuso Sexual em } \\
\text { casa relatado para } \\
\text { o(a) professor(a) } \\
\text { (DF) }\end{array}$ & 2 & 17 & 7 & 0 & 1 & 47 \\
\hline 5 & $\begin{array}{c}\text { Pergunta sobre sexo } \\
\text { na aula (DM) }\end{array}$ & 3 & 38 & 0 & 9 & 0 & 5 \\
\hline 6 & $\begin{array}{l}\text { Comportamento } \\
\text { inadequado: } \\
\text { exposição pública do } \\
\text { corpo nu na sala de } \\
\text { aula (TEA) }\end{array}$ & 2 & 38 & 12 & 7 & 0 & 25 \\
\hline \multicolumn{2}{|c|}{ Total no de respostas } & 22 & 180 & 75 & 33 & 15 & 102 \\
\hline
\end{tabular}

Fonte: Elaborada pelas autoras a partir dos dados da pesquisa.

Legendas: (*): (DI) Deficiência Intelectual. (DV) Deficiência Visual. (DA/S) Deficiência Auditiva/Surdez. (DF) Deficiência Física. (DM) Deficiência Múltipla. (TEA) Transtorno do Espectro Autista.

Podemos observar nas respostas em diferentes classes que o "diálogo" (n=180), tentando resolver a situação foi frequente como uma atitude provável dos (as) professores (as), especialmente com o aluno com deficiência intelectual e com os alunos com surdez. Curiosamente, também nesses casos, a "solicitação de ajuda" (n=102) foi frequente, devido à dificuldade de comunicação e a falta de habilidades para lidar com as condições específicas da deficiência, como, por exemplo, o domínio da Língua Gestual $^{4}$. Uma terceira atitude frequente foi a "correção do comportamento" $(n=75)$, o que é comum no professorado. A "tolerância" $(n=15)$ apareceu nos casos com os alunos cegos e autistas, justamente quando a diferenciação necessária entre público e privado e/ou noções de privacidade nas relações sociais eram mais precárias: assédio no toque e exibicionismo. A atitude de "assumir dificuldades" $(n=22)$ para lidarem com as situações apareceu nos casos do aluno autista que fica nu na sala de aula e da menina com deficiência física que relata um caso de abuso sexual por parte do avô. E o "diálogo esclarecedor" ( $\mathrm{n}=33)$ com o aluno e os demais colegas ocorreu mais na situação do aluno com deficiência intelectual que se masturba na sala de aula.

$\mathrm{Na}$ situação em que o aluno com autismo/TEA exibe seu corpo diante dos colegas, os (as) professores (as) preocuparam-se também com os demais alunos da sala. $\mathrm{O}$ caso do assédio do aluno cego pareceu mais perturbador e houve quem permitisse o toque indevido "por ser uma intenção de conhecimento" e também quem assumisse ter, nesse caso, “dificuldades para reagir". O caso da violência sexual relatada pela aluna com deficiência física foi encarado com muita seriedade por parte dos (as) professores

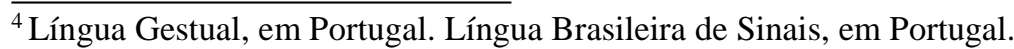


(as) que, embora não relatassem muitas ações em relação à menina, mostraram-se preparados para a necessidade de averiguação e denúncia.

\section{Análise qualitativa das respostas dos (as) professores (as) diante das situações projetivas}

Se organizarmos os relatos com uma análise qualitativa de conteúdo, podemos desvelar as diferentes possíveis ações dos (as) professores (as) em cada situação, a partir das categorias temáticas emergentes, comentadas, a seguir. Em cada uma das situações apresentamos as categorias, seguidas de um dos relatos dos (as) professores (as), como exemplo.

Masturbação de um aluno com deficiência intelectual na sala de aula

Diante da situação, os (as) professores (as) disseram que tomariam uma atitude imediata em relação ao ocorrido, conversando com o aluno diretamente sobre o fato de ser um comportamento inadequado. A postura deles pareceu ser a de orientar que tocar na genitália não deveria ser feito naquele lugar e controlar a situação. É interessante perceber que houve também uma preocupação em relação aos demais alunos da sala de aula, no sentido de fazer com que eles "respeitassem e compreendessem o comportamento do colega com deficiência". Além disso, em alguns casos, "recorreriam a ajuda de funcionários ou relatariam a ocorrência ao diretor", evidenciando uma atitude dos (as) professores (as) que envolve outras pessoas na escola.

Aqui, três categorias foram identificadas sobre as possíveis atitudes dos (as) professores (as): (a) Conversava com o aluno elou corrigia seu comportamento: "Primeira reação era pedir que levantasse as calças, depois falaria com ele e diria que devemos ter cuidados, que têm meninos e meninas lá, que todos têm seu espaço"; (b) Conversava com os demais alunos da sala de aula: "Minha reação seria me dirigir às outras crianças que estavam lá para acalmar", "Eu diria que o João tem as suas características e que possivelmente ele nem se apercebeu, mas têm certos sentimentos e não sabia distinguir certas situações", "tentava dar volta na situação e dizer que João tem as mesmas necessidades, mas não sabia controlar-se"; (c) Pediria ajuda a alguém: "Provavelmente chamar alguém da educação especial da unidade para ficar com o João e me ajudar". 
Destacamos também o comentário de uma professora: "Eu pediria para colocar as calças e ir lavar as mãos, diria que precisa guardar sua joia e usar o banheiro se precisar olhá-lo", relacionando o controle do corpo (toque e prazer) às questões de higiene e à valorização do pênis, dando menos ênfase a diferença entre comportamento público e privado.

Comportamento inadequado: toques corporais indevidos de aluno cego com um professor

No caso do aluno cego que pede para tocar o corpo do professor querendo conhecê-lo, a tolerância do comportamento invasivo apareceu, no sentido de considerar a intencionalidade de "conhecimento", como se isso desprovesse o conteúdo erótico inerente ou porque o professor preferiu se omitir e se afastar da situação. É interessante destacar que tanto os alunos com deficiência, quanto os que não têm, se emitissem esse comportamento a intenção seria dupla em ambos os casos: pelo prazer do toque e pela curiosidade em conhecer as diferenças anatômicas. Assim, seria improvável que algum professor tolerasse tal atitude de alunos sem deficiências, pois nesse caso, seriam atribuídos à consciência do sentimento de prazer envolvido em tal comportamento.

Nos relatos, houve quem tolerasse a situação ou quem ignorasse, como se ter a "deficiência" justificasse o comportamento, esquecendo a importância do esclarecimento de regras e dos limites que esses alunos com cegueira devem aprender sobre intimidade e privacidade. Em muitas situações, apesar dos professores relatarem alguma reação diante do fato, a ajuda de colegas e/ou de profissionais da área da Psicologia e/ou educação especial pareceu uma alternativa importante, talvez para dar maior respaldo nas ações, assumidamente, inseguras pelo professor.

Aqui, quatro categorias foram identificadas sobre as possíveis atitudes dos (as) professores (as): (a) Não faria nada, aceitaria o toque do aluno cego: "Se eu visse que aquilo era uma coisa pura, falava com a turma, -este menino quer saber o que é uma mama - e deixava ele por a mão, quer dizer, eu colocava a mão dele, para saber onde está indo"; (b) Não permitiria o toque do aluno cego: "Eu ia, pedir de forma educada que não fizesse, mas se fosse intencional, iria dizer claramente que não"; (c) Aproveitaria a situação, explicando sobre o corpo: "Conversava com o aluno e mostrava um modelo anatômico existente na sala de ciências para sentir com o tato" e (d) Sentiria desconforto: "Provavelmente sentir-me-ia envergonhada". 
Namoro entre aluna e aluno surdos dentro do banheiro da escola

O namoro de alunos surdos na escola, em geral, não foi compreendido como um problema e alguns (mas) professores (as) apontaram que isso ocorre entre vários de seus (uas) alunos (as) que não têm deficiência. Já a troca de afeto dentro de um banheiro na escola foi um comportamento tanto compreendido como algo próprio da idade dos alunos, quanto como um "problema mais grave". O foco do inadequado diz respeito ao local em que esse comportamento ocorre. Primeiro porque um dos dois (como se tratava de um casal heterossexual) estava, na fala dos (as) professores (as), em banheiro não destinado ao seu sexo e, segundo, que o namoro poderia ser tolerado no espaço da escola, mas não escondido em um banheiro.

Houve quem lembrasse que na tentativa de dialogar com os alunos surdos haveria dificuldade na comunicação quando não se domina a língua gestual/libras; outros recorreriam ao (a) professor (a) de educação especial, que sabemos, pode não estar disponível.

Aqui, cinco categorias foram identificadas sobre as possíveis atitudes dos (as) professores (as): (a) Lidaria com os alunos a partir das regras gerais da escola sobre o uso do banheiro: "Ia lá e fazia entender que teriam que cumprir as regras - não podiam estar os dois na mesma casa de banho [=banheiro]"; (b) Pediria ajuda de um professor da educação especial: "Chamava a professora de língua gestual, pois conseguiriam comunicar normalmente com eles"; (c) Acredita que o namoro e o beijo são permitidos, o local (banheiro) é que é inadequado: "É um comportamento normal e eu diria que fizesse em outro sítio [=lugar], nada mais que isso"; (d) Considera o comportamento reprovável e toma providências radicais: "Falaria com eles em privado e provavelmente chamaria os pais à escola"; (e) Não se importaria: "Dependendo da idade dos alunos, provavelmente deixava que se beijassem sem interferir".

Relato de aluna com deficiência física sobre ocorrência de abuso sexual pelo avô.

Foi marcante a preocupação dos (as) professores (as) em acolher, conversar e denunciar a situação da aluna contar um caso de abuso sexual cometido pelo avô, em casa. Entretanto, alguns (umas) professores (as) titubearam em julgar se se tratava de uma ocorrência de violência ou um afeto. Pensaram em investigar com a família, conversar com outras pessoas, sem serem enfáticos com a menina que era uma violência inaceitável. Evidentemente que não era um caso de afeto, mas de uma relação de abuso 
de poder e exploração diante de uma situação vulnerável de que alguém menor de idade com uma deficiência física e grande comprometimento motor com dependência de cuidadores. Mais sério ainda foi perceber em alguns relatos uma certa culpabilização da menina, como se ela permitisse que situação com o avô acontecesse.

Aqui, três categorias foram identificadas sobre as possíveis atitudes dos (as) professores (as): (a) Colocaria em dúvida a gravidade da situação: "Penso que o avô só a estava a ajudar a lavar-se e que é normal dar um beijinho de boa noite"; (b) Procuraria conversar com outras pessoas e denunciaria: "Eu sentiria obrigado a participar essa ocorrência a nível superior, provavelmente à comissão de proteção de menores e jovens em situação de risco tendo em conta que é uma menor, é... digamos um crime". (c) Acolheria e se preocuparia com a aluna: "Não dizia que ela a tinha culpa ou coisa do gênero, mas que não era o melhor comportamento ou o mais adequado entre o avô e neta e seria melhor pedir a outra pessoa para lhe dar o banho, para ajudar e evitar esses contatos com o avô".

Pergunta sobre sexo de uma aluna com deficiência múltipla na sala de aula

De modo geral, os (as) professores (as) não se omitiram diante da pergunta da aluna sobre sexo na sala de aula. Embora tivessem a preocupação de atender a demanda da aluna, diante dos demais alunos, alguns (umas) professores (as) mostraram mais facilidades que outros (as), em relação a como agir.

Aqui, três categorias foram identificadas sobre as possíveis atitudes dos (as) professores (as): (a) Explicaria para a aluna e para toda a sala de aula, tentando ser "natural": "Iria explicar de alguma forma que é uma relação natural do ser humano...que segue certas regras, iria tentar explicar o que isso era, na realidade...para todos os alunos, para não ter problemas"; (b) Explicaria com eufemismos, de modo evasivo: "Começaria por dizer que sexo é tão simplesmente aquilo que diferencia os meninos das meninas"; (c) Diria que responderia depois: "Marcava um momento posterior para conversar com ela e esclarecer".

Comportamento inadequado de exposição pública do corpo de aluno com autismo/TEA na sala de aula

Lidar com o comportamento de um aluno com autismo (TEA) diante de um teste requer dos (as) professores (as) ações mais complexas na medida em que outras variáveis estão envolvidas, pois além da nudez pública do aluno, o seu nervoso e 
descontrole ainda poderia "atrapalhar os demais alunos na prova que realizam". Houve professores (as) que se preocuparam com os demais alunos que poderiam se sentir prejudicados no teste pela confusão causada na sala de aula.

Aqui, foram quatro categorias identificadas sobre as possíveis atitudes dos (as) professores (as): (a) Iria preocupar-se com os demais alunos da sala de aula: "Respirava fundo!... na situação em concreto tentaria que o restante dos alunos mantivesse a calma e concentração necessária para continuar o teste"; (b) Tentaria acalmar o aluno autista quanto à prova: "Depois ele faria outro teste, tinha primeiro que acalmá-lo, e depois de acalmar, falava com ele e agendar-te-ia outra data"; (c) Iria corrigir o comportamento da nudez pedindo ou exigindo que o aluno autista vestisse a roupa: "Iria tentar que ele vestisse a roupa, não podia fazer o teste completamente pelado" (risos); (d) Pediria ajuda: "Chamaria as colegas do ensino especial, equipe de psicólogos da escola”.

Destacamos o comentário de um professor: "Procurava impor-lhe silêncio e obrigava-o a ficar quieto, mesmo que, para isso, tivesse de usar força física, que mostra uma postura mais autoritária" ("impor", "obrigar", "usar força física"), que seria bem complicada diante do aluno com autismo, podendo aumentar o descontrole do mesmo.

\section{Discussão}

A postura mais comum dos (as) professores (as), diante das situações projetivas, foi resolver o problema dialogando com o (a) aluno (a) para "controlar" ou "extinguir" o comportamento diante dos (as) colegas da sala, mesmo que, para isso, tenha sido necessário contar com a ajuda de outras pessoas, principalmente professores (as) da educação especial, psicólogos (as) e dirigentes que atuam na escola.

Ao serem indagados (as) sobre o que fariam diante da "cena", a finalidade principal das atitudes relatadas foi o controle da situação como "resolvendo um problema", mas os (as) professores (as) não ampliaram a discussão para propostas de ações futuras, isto é, o que poderia ser feito em Educação Sexual para esses (as) alunos (as) para que tais comportamentos fossem evitados ou não voltassem a ocorrer, na direção de processos educativos preventivos, como apontam Pérez (2014), Vieira e Coelho (2014) e Wild et al. (2014).

Os comportamentos citados nas situações ocorrem, em grande parte, pela falta de diálogo e de esclarecimentos com os (as) alunos (as) em casa ou na escola, ou pelas 
informações sobre as regras sociais não terem sido acessíveis e compreendidas por eles (as). Jovens com deficiências podem desenvolver comportamentos adequados e semelhantes a outros jovens sem deficiências, como evidenciam autores que realizaram processos de Educação Sexual junto às pessoas com deficiências intelectuais e/ou problemas de aprendizagem (COUWENHOVEN, 2007; HAYASHI; ARAKIDA; OHASHI, 2011; SWANGO-WILSON, 2011), às pessoas com deficiências sensoriais (KAPPERMAN; KELLY, 2013), com deficiências físicas (EAST; ORCHARD, 2013; PORAT; HERUTI; NAVON-PORAT; HARDOFF, 2012) e também com Transtorno do Espectro Autista (BARNETT; MATICKA-TYNDALE, 2015; CURTISS; EBATA, 2016).

De qualquer forma, os (as) professores (as) colocaram-se na posição de "resolverem a situação imediatamente", sem pensarem nos antecedentes e consequentes, tanto diante dos comportamentos emitidos, quanto de suas ações diante deles. É papel dos (as) professores (as) assumirem a Educação Sexual na escola, seja por força de uma legislação que impõe essa tarefa como uma educação intencional e sistematizada, seja por se reconhecerem educadores sexuais, pois a educação informal e assistematica é constante nas instituições, como afirmam os autores Matos, Reis, Ramiro, Ribeiro e Leal (2014), Nodin (2002) e Vilaça, (2017).

Alguns (umas) professores (as) preocuparam-se com os (as) colegas da sala, seja para repreendê-los (as) por "provocarem" o comportamento inadequado do aluno com deficiência, seja para esclarecê-los (as) e pedir a eles (as) que compreendam a situação. De qualquer forma, foi interessante perceber o olhar desses (as) professores (as) para uma sala de aula inclusiva em que há sempre uma relação entre os (as) alunos e isso evidencia os benefícios para todos e todas dos princípios da inclusão (HEHIR et al., 2016).

A tolerância por parte de alguns (umas) professores (as) em aceitar os toques do aluno cego pareceu ocorrer pela tentativa de colaborar com a sua necessidade de ter acesso ao conhecimento. Talvez, esses (as) professores (as) tenham uma compressão equivocada dos limites que devem ser estabelecidos entre professor (a) e aluno (a), mas o que parece é que a imposição do limite tem a ver com a percepção do teor erótico, mais facilmente atribuído aos (às) alunos (as) que não têm nenhuma deficiência - que mesmo argumentando apenas conhecimento, provavelmente não teriam anuência do (a) professor (a) para essa proximidade. Isso sugere que pode estar presente a ideia da assexualidade ou de uma sexualidade ingênua e angelical nas pessoas com deficiências 
quando foram permitidos elas esses toques corporais, reproduzindo os mitos sobre a sua sexualidade, apontado pelos autores Anderson (2000), Giami (2004) e Maia e Ribeiro (2010).

A busca pela ajuda de outros (as) profissionais, principalmente professores (as) da educação especial, mostra também que os (as) participantes não têm uma formação plena na educação inclusiva que lhes permitiriam agir com segurança. Por exemplo, como dialogar com alunos (as) com surdez, se não há domínio da língua gestual/libras? Se essa dificuldade apareceu na situação do namoro no banheiro, é possível prever que ela também existiria em outros contextos educativos, até mesmo na sala de aula.

O (A) profissional da educação especial na escola não deve ser um "salva-vidas" e ele (a) tampouco estará presente a todo momento em todas as salas de aulas. Isso reforça ainda mais o despreparo de toda a equipe escolar que poderia garantir aos (a) alunos (as) com deficiência o acesso com as devidas adaptações curriculares, recursos e materiais com acessibilidade, tecnologias assistivas etc., isto é, fatores que ainda dificultam o processo de inclusão dos (as) alunos (as) com deficiências nas escolas regulares: problemas na estrutura da escola, falta de profissionais técnicos especializados e formação dos (as) professores (as).

Alguns (umas) professores (as) assumiram certas dificuldades diante da projeção. Em alguns casos, admitiram "não saber agir" na Educação Sexual de alunos (as) com deficiência, o que também foi registrado nos estudos de Aderemi (2014), Maia, Reis-Yamauti, Schiavo, Capellini e Valle (2015) e Wilkenfeld e Ballan (2011). Responderam, evidentemente, a partir de suas experiências, pelo bom senso e pela prática cotidiana no trato de quaisquer alunos (as). Embora os (as) professores (as) tenham mostrado uma disposição favorável em responderem diante das manifestações sexuais de seus (uas) alunos (as) com deficiências com diálogo, acolhimento e respeito, as atitudes para "resolver" as situações foram improvisadas, pois ainda demonstram uma formação precária em relação a que deveriam ter. E já na situação da coleta de dados, alguns (umas) professores (as) sinalizaram a necessidade de receberem tal formação, defendida também pelas autoras Albuquerque e Almeida (2010) e Maia et.al. (2015).

Neste sentido, uma formação aos (às) professores (as) sobre Educação Sexual para o público alvo da educação especial na perspectiva da educação inclusiva pode colaborar em ações seguras pautadas em orientações científicas que ajudariam em todos os sentidos: tranquilidade do (a) professor (a) em agir nessas situações sem precisarem 
recorrer a especialistas ou a outras pessoas, a inserção dessa temática no currículo escolar dos (as) alunos (as) e na proposta de toda a escola, a diminuição dos comportamentos inadequados dos (as) alunos (as) com deficiência e, também, na interação respeitosa entre esses (as) alunos (as) e seus (uas) colegas de desenvolvimento típico.

Os dados encontrados retificam a literatura sobre as concepções de professores (as) sobre educação sexual inclusiva e, considerando o contexto português em que foi realizada esta pesquisa onde a Educação Sexual nas escolas é lei, tornou-se mais necessário ressaltar a importância de se investir na formação em temas como sexualidade, gênero e desenvolvimento humano, desses (as) profissionais, principalmente, considerando as especificidades nos comportamentos daqueles que têm deficiências, altas habilidades/superdotação ou transtornos globais do desenvolvimento.

\section{Considerações finais}

Embora os (as) professores (as) desta pesquisa mostrem uma disposição favorável em considerar seus (uas) alunos (as) com deficiência como seres sexuais e respondem diante de seus comportamentos com diálogo, acolhimento e respeito, as atitudes para "resolverem" as situações que consideram "problemáticas" são improvisadas, pois ainda é a precária a formação que deveriam ter tanto na educação especial, quanto na educação sexual inclusiva.

Podemos considerar que as situações fictícias, envolvendo comportamentos de alunos (as) com deficiência ou outras condições, que existiram ou poderiam existir na prática profissional cotidiana desses (as) professores (as) desencadearam relatos sobre suas concepções e possíveis ações e, assim, configurou-se um importante instrumento para a projeção, levando a um momento de percepção da própria limitação formativa e/ou insegurança que podem sentir diante dessas ocorrências e a necessidade de refletirem sobre isso.

O uso das situações - cenas - sobre as expressões da sexualidade de alunos (as) com deficiência e com TEA nas escolas inclusivas foi um recurso interessante e pode ser utilizado como instrumento de pesquisa, mas também como recurso pedagógico, em cursos de formação, para reflexão e estratégias de reflexão e debate.

Como um estudo qualitativo há limitações que não nos permitem levantar hipóteses ou tecer generalizações e outras pesquisas mais aprofundados poderão 
aprofundar os dados e levantar novas discussões, lembrando que analisamos fontes indiretas, que são os relatos e não as ocorrências reais das situações, nas quais, sem dúvidas envolveriam diversas outras variáveis.

De qualquer forma, acreditamos que os (as) professores (as) portugueses também necessitam de formação para lidarem com a Educação Sexual de alunos (as) que compõe o público alvo da educação especial na escola e que as situações projetivas - estas apresentadas neste artigo ou outras que podem ser elaboradas, são boas estratégias tanto para o levantamento de concepções, como para serem utilizadas como instrumentos pedagógicos em cursos de formação.

\section{Referências}

ADEREMI, T. J. Teachers' perspectives on sexuality and sexuality education os learners with intellectual disabilities in Nigeria. Sex Disability, v. 32, p. 247-258, 2014.

ALBUQUERQUE, P. P.; ALMEIDA, M. A. Sexualidade e deficiência intelectual: um curso de capacitação de professores. Revista Brasileira de Estudos Pedagógicos, v. 91, n. 228 , p. 408-423, 2010.

ANDERSON, O. H. Doing what comes naturally? Dispelling myths and fallacies about sexuality and people with developmental disabilities. Illinois: High Tide Press, 2000.

BARDIN, L. Análise de conteúdo. (RETO, L. A.; PINHEIRO, A., Trads.). Lisboa: Edições 70, 2011.

BARNETT, J.P.; MATICKA-TYNDALE. Qualitative exploration of sexual experiences among adults on the autism spectrum: implications for sex education. Perspectives of Sexual and Reproductive Health, v. 47, n. 4, p. 171-179, 2015.

BORTOLOZZI, A.C.; VILAÇA, T. Educação Sexual Inclusiva e a Formação de Professores (as). São Paulo: Cultura Acadêmica Unesp, 2020. 180p.

BLACKBURN, M. Sexuality and Disability. Oxford, UK: Butterworth Heinemann, 2002.

BRASIL. Ministério da Educação. Política Nacional de Educação Especial na Perspectiva da Educação Inclusiva, Brasília: MEC/SEF, 2008. Disponível em: http://portal.mec.gov.br/arquivos/pdf/politicaeducespecial.pdf.Acesso em: 19. Abr. 2020. 
CÉSAR, M. R. de A. Gênero, sexualidade e educação: notas para uma "Epistemologia". Educar, v. 35, p.37-51, 2009.

CHIRAWU, P., HANASS-HANCOCK, J,. ADEREMI, T. J., REUS, L., HENKEN, A. S. Protect or Enable? Teacher's Beliefs and Practices regarding provision os sexuality education to learners with disability in KwaZulu-Natal, South Africa. Sex Disability, v. 32, p. 259-277, 2014.

COUWENHOVEN, T. Teaching children with Down Syndrome about their bodies, boundaries and sexuality - a guide for parents and professionals. Bethesda/USA: Woodbine House, 2007.

CURTISS, S. L.; EBATA, A.T. Building Capacity to deliver Sex Education to individuals with Autism. Sexual Disability, v. 34, p. 27-47, 2016.

EAST, L. J.; ORCHARD, T. R. Somebody Else's Job: Experiences of Sex Education among Health Professionals, Parents and Adolescents with Physical Disabilities in Southwestern Ontario. Sex Disabil, v. 32, p. 335-350, 2013.

FRANÇA-RIBEIRO, H. C. Direitos sexuais e pessoas com deficiência: conquistas e impasses. In: RIBEIRO, P.R.M.; FIGUEIRÓ, M.N.D. (Orgs). Sexualidade, cultura e educação sexual: propostas para reflexão. São Paulo: Cultura Acadêmica, 2004. p. 965.

GIAMI, A. O anjo e a fera: sexualidade, deficiência mental, instituição. (MACEDO, L. Trad.). São Paulo: Casa do Psicólogo, 2004.

HAYASHI, M.; ARAKIDA, M.; OHASHI, K. The effectiveness of a sex education program facilitating social skills for people with intellectual disability in Japan. Journal of Intellectual \& Developmental Disability, v. 36, n. 1, p. 11-19, 2011.

HEHIR, T., GRINDAL,T., FREEMAN, B., LAMOREAU, R., BORQVAYE,Y., BURKE, S. Os benefícios da educação inclusiva para estudantes com e sem deficiências. São Paulo: Instituto LANA; ABT Association, 2016.

KAUFMAN, M.; SILVERBERG, C.; ODETTE, F. The ultimate guide to sex and disability - for all of us who live with disabilities, chronic pain e illness. 2 a ed. Califórnia/USA: Cleis Press, 2003.

KAPPERMAN, G.; KELLY, S. M. Sex Education Instruction for Students who are visually impaired: recommendations to guide practitioners. Journal of Visual Impairment \& Blindness, v. 107, n. 3, p. 226-230, 2013. 
MAIA, A. C. B.; RIBEIRO, P. R. M. Desfazendo mitos para minimizar o preconceito sobre a sexualidade de pessoas com deficiência. Revista Educação Especial, v. 16, n. 2, p. 159-176, 2010.

MAIA, A. C. B.; RIBEIRO, P. R. M. Educação Sexual: princípios para a ação. Doxa Revista Paulista de Psicologia e Educação, v. 15, n. 1, p. 41-51, 2011.

MAIA, A. C. B., REIS-YAMAUTI, V. L., SCHIAVO, R. A., CAPELLINI, V. L. M. F.; VALLE, T. G. M. Opinião de professores sobre a sexualidade e a educação sexual de alunos com deficiência intelectual. Estudos de Psicologia, v. 32, n. 3, p. 427-435, 2015.

MAIA, A.C.B.; VILAÇA, T. Sexualidade e Deficiência: apontamentos sobre a educação sexual na escola inclusiva. In: RIZZA, J.L.; MAGALHÃES, J. C.; RIBEIRO, P. R.C.; COSTA, A.L. C. (Orgs.). Tecituras sobre corpos, gêneros e sexualidades no espaço escolar. Rio Grande: Ed da Furg, 2019. 312p.

MATOS, M. G.; REIS, M.; RAMIRO, L.; RIBEIRO, J. P.; LEAL, I. Educação sexual em Portugal: legislação e avaliação da implementação nas escolas. Psicologia, Saúde \& Doenças, v.15, n. 2, p. 335-355, 2014.

NODIN, N. Sexualidade de A a Z. Lisboa: Bertrand Ed, 2002.

PÉREZ, M. del P. C. Mitos acerca de la maternidad em mujeres com discapacidad. Perinatología y reproducción humana, v. 28, n. 2, p. 91-96, 2014.

PORAT, O.; HERUTI, R.; NAVON-PORAT, H.; HARDOFF, D. Counseling Young People with Physical Disabilities Regarding Relationships and Sexuality Issues: Utilization of a Novel Service. Sexuality and Disability, v. 30, n. 3, p. 311-317, 2012.

REUS, L.; HANASS-HANCOCK, J.; HENKEN, S.; BRAKEL, W. V. Challenges in providing HIV and sexuality education to learners with disabilities in South Africa: the voice of educators. Sex Education, v.15, n. 4, p. 333-347, 2015.

SAMPIERI, R. H.; COLLADO, C. H.; LUCIO, P. B. Metodologia de Pesquisa. (F. C. MURAD, F.C.; KASSNER, M.; LADEIRA, S. C. D., Trads). $3^{\text {a }}$ ed. São Paulo: McGraw-Hill, 2006.

SWANGO-WILSON, A. Meaningful sex education programs for individuals with intellectual/developmental disabilities. Sex Disability, v. 29, p. 113-118, 2011.

UNESCO. Organização das Nações Unidas para a Educação, Ciência e Cultura (2014). Orientações técnicas de educação em sexualidade para o cenário brasileiro: tópicos e objetivos de aprendizagem. Brasília: Unesco, 2014. Disponível em: https://unesdoc.unesco.org/ark:/48223/pf0000227762. Acesso em 19. Abr.2020. 
VIEIRA, C. M.; COELHO, M. A. Sexualidade e deficiência intelectual: concepções, vivências e o papel da educação. Revista Tempos e Espaços em Educação, v. 7, n. 13, p. 201-211, 2014.

VILAÇA, T. A multiple case study based on action-oriented sexuality education: Perspectives of Portuguese teachers. Health Education, v. 117, n. 1, p. 110-126, 2017.

VILELA, M. H. Q. B. Diferente mas não desigual - a sexualidade no deficiente intelectual. 2. ed. São Paulo: Trilha Educacional, 2016. 93 p.

WILD, T. A.; KELLY, S. M.; BLACKBURN, M. V.; RYAN, C. L. (2014). Adults with visual impairments report in their Sex Education experiences. Journal of Blindness Innovation \& Research, v. 4, n. 2, s/p. Disponível em: https://www.nfb.org/images/nfb/publications/jbir/jbir14/jbir040202.html. Acesso em: 19. Abr. 2020.

WILKENFELD, B. F.; BALLN, M. S. Educators attitudes and beliefs towards the sexuality of individuals with developmental disabilities. Sex Disabil, v. 29, n. 4, p. 351261, 2011.

Recebido em abril de 2020.

Aprovado em maio de 2020. 